\title{
Monitoring and Evaluation of Medication Error in a Tertiary Care Hospital
}

\author{
Yadhukrishnan $\mathrm{P}^{1^{*}}$, Nolin Johncy ${ }^{2}$, Shilpa $\mathrm{R}^{3}$, Naveen Kumar $\mathrm{P}^{3}$, Mohamed Thayub $\mathrm{S}^{4}$, Daniel \\ Sundar Singh, $\mathrm{S}^{3}$ \\ ${ }^{\mathrm{T}}$ Department of Clinical Pharmacy, Indiana Hospital and Heart Institute, Mangalore, Karnataka, India \\ ${ }^{2}$ Department of Pharmacy Practice, Srinivas College of Pharmacy, Mangalore, Karnataka, India \\ ${ }^{3}$ Department of Pharmacy Practice, C.L. Baid Metha College of Pharmacy, Chennai, Tamil Nadu, India \\ ${ }^{4}$ Department of Clinical Pharmacy, Frontier Lifeline Hospital, Chennai, Tamil Nadu, India
}

\section{*Corresponding Author}

Yadhukrishnan P U

\author{
Article History \\ Received: 26.02 .2020 \\ Accepted: 05.03.2020 \\ Published: 08.03.2020
}

\begin{abstract}
Background: A medication error is a failure in the treatment process that leads to potential harm to the patient. Objectives: The study aimed to detect common prescribing and dispensing medication errors and frequency of medication errors reported by healthcare providers (HCP). Methodology: This observational prospective study was conducted for 10 months from January 2019 to October 2019 in an inpatient setting of a tertiary care hospital in Mangalore using Incident reporting form. The severity levels of medication errors have been analyzed by using the National Coordinating Council for Medication Error Reporting and Prevention (NCCMERP) proposed index for categorizing medication errors. Results: On evaluating the medication errors, $30.18 \%$ were prescribing errors, $22.64 \%$ were dispensing errors. Majority of the errors were reported by Clinical pharmacist (62.6\%), followed by Nurses (24.52\%). The drugs acting on CVS were the most common class of drugs in which errors occurred (27\%). Most of the errors in our study resulted in (Error No Harm) $86.3 \%$ (category B, C and D), (No Error) $13.5 \%$ (category A), $1.2 \%$ (category E, F, G, H) resulted in (Error Harm). No incidence of Error Death was reported. Conclusion: The incidence of medication errors was significantly high and it is essential to establish medication error reporting system and the educational programme for drug prescribers and nurses concerning drug therapy are urgently needed to avoid medication errors and to improve patient safety by clinical pharmacists.
\end{abstract}

Keywords: medication error, (HCP), (NCCMERP), Monitoring.

\section{INTRODUCTION}

Medication errors have been defined broadly as "any error in prescribing, dispensing, or administration of drugs. Irrespective of whether such errors lead to adverse consequences or not". They are essentially failures of the treatment process that lead to potential harm to the patients. Incidence rate of adverse drug events amongst adults admitted to the hospital have ranged from 2 to 7 per 100 admissions. Almost 28\% of adverse drug events (ADEs) are related to medication errors. They are regarded as the most preventable causes of patient harm with significant contributions to adverse drug events occurrences in hospitalized patients. Such adverse drug events due to preventable medication errors lead to prolonged hospital stay, significant increases in cost of care and occasionally to death.

Causes of medication errors varies according to the aspect of the treatment process considered i.e. prescribing, transcribing manufacturing or compounding, dispensing and administration of drugs as well as monitoring of therapy. According to the American Society of Health-System Pharmacist (ASHP) in 2014, medication errors may include "prescribing errors, omission errors, wrong time errors, and unauthorized drug errors, wrong dosage form errors, improper dose error, wrong drug preparation errors, and wrong administration or technique errors, monitoring errors, deteriorated drug errors, compliance errors". Errors arise when an action is intended but not performed; errors that arise from poor planning or inadequate knowledge are characterized as mistakes; those that arise from imperfect execution of

Copyright @ 2020: This is an open-access article distributed under the terms of the Creative Commons Attribution license which permits unrestricted use, distribution, and reproduction in any medium for non commercial use (NonCommercial, or CC-BY-NC) provided the original author and source are credited. 
well-formulated plans are called slips when an erroneous act is committed and are called lapses when a correct act is omitted. The leading causes behind other types of medication errors comprise of clogging of health- care professionals with enormous patients because of alarming shortage of health- care professionals, especially in developing countries like India, miscommunication amongst the health- care team. Confusing or misleading drug labeling, packaging, nomenclature of medicines, lack of knowledge about drug therapy also causes medication errors. Misinterpretation of verbal orders, conservative approach of health- care professionals in taking patient history for example ignorance of taking the allergy history of the patient are few other causes of occurrence of medication errors [1]. Drug use is a complex process and there are many drug related challenges at various levels, involving doctors, pharmacists, nurses and patients. Medication misadventure can occur anywhere in the health care system and many errors are preventable and pharmacists have an active role in the appropriate use of drugs [2].

Medication errors are of major concern because they result in significant morbidity, mortality and health care costs. The objectives of this study are as follows:

- To detect common prescribing and dispensing medication errors.

- To detect the frequency of medication errors reporting by healthcare providers (HCP).

\section{Methodology}

\section{Study Design and Site}

This observational and cross-sectional study was conducted for 10 months from January 2019 to October 2019 in an inpatient setting of a tertiary care hospital in Mangalore.

\section{Study Tool}

A) Medication error reporting form

B) NCCMERP index for determining severity level of medication errors

\section{Data Collection Method \\ Participants \\ Inclusion Criteria}

Patients of all age groups, either sex and only in wards and critical units were included.

\section{Exclusion Criteria}

Known allergies or previous history given by patients regarding drug allergies are excluded from this study. OPD patients are also excluded. The use of alternative system of medicines such as Ayurveda, Homeopathy, Unani etc as well as over dosage, excess consumption, was excluded. Patients who are mentally retarded, drug addicted, suicidal tendencies or consumption of a drug in the influence of alcohol was also excluded.

\section{RESULTS AND DISCUSSION}

In our study a total of 53 medication errors were found among them $32.18 \%$ were prescribing errors, $22.64 \%$ were dispensing errors followed by $16.98 \%$ of documentation errors. Transcription errors were found to be $7.54 \%$ while $3.74 \%$ of errors were of billing and patient identification errors (Table-1). Prescribing errors $(82.80 \%)$ is the most common among them. Root-cause of these MEs was distractions, workload, and communications. Which is similar to the study conducted by Lustig A(3). Study done by Karthikeyan et al., [4] dispensing of wrong medication was accounted the most as dispensing error. (22.66 \%) of errors were caused by dispensing the wrong drug was observed in our study.

Out of prescribing errors, therapeutic duplication was seen the most which consist of (37.5\%) of errors and which can lead to serious health impacts. Wrong dose which comprised of (31.25\%) was seen which can lead to increase or decrease of amount of drug reaching the body. Illegible handwriting in (12.5\%) of cases was found to be another important reason for the occurrence of medication errors that may lead to dispensing the wrong drug to wrong patient. $(6.25 \%)$ of errors were prescribing wrong time when the drug should be consumed and details of patient missing (Table2).

Among various serious errors related to dispensing, (75\%) of errors were caused by dispensing the wrong drug followed by $(25 \%)$ dispensing the wrong dosage of the specific drugs. Incorrect route of administration of the drug and dispensing poorly conditioned drugs comprised of (8.33\%) of errors (Table-3). The reason for the error are peak hour, improper stock arrangements and storage problem and staffing insufficient. This study was similar to the study conducted by Kenneth NB et al., [5]. 
In our study setting, majority of the errors were reported by Clinical pharmacist $(62.6 \%)$ compared to other health care professionals (Figure-1). Thus a clinical pharmacist initiated non punitive anonymous ME reporting system could improve patient safety, safety, this study was supported by the chalasani HS et al., [6].

Severity level assessment analysis of medication errors was done according to NCCMERP Index for Categorizing Medication Errors. Most of the errors in our study resulted in error No Harm $86.5 \%$ (category B, C and D), No Error $13.5 \%$ (category A), $1.2 \%$ (category E, F, G, H) resulted in Error Harm. No incidence of Error Death was reported due to medication errors as shown in Table-5. Based on these findings, medication error preventive strategies were developed accordingly, example high risk medication tags to caution the end users, separation of look-alike and sound-alike drugs and train pharmacists etc. The results found in our study were comparable to the study conducted by Manjunath Gandage [7].

In this study, we found that medication error was more with drugs acting on CVS 11 (20.7\%), antibiotics 7 (13.2\%), anti thrombolytics 6 (11.3\%), drugs acting on CNS and vitamin supplements $5(9.43 \%)$, anti histamine ,drugs acting on respiratory, sedative and hypnotics $4(7.54 \%)$, steroids $2(3.77 \%)$,followed by diuretics and anti malarial 1 $(1.88 \%)$. Study conducted by LaPointe NM et al (8) also found CVS drugs were most common class of drugs involved in medication errors $(41.2 \%)$. Study suggests that CVS class of drugs need special focus.

Table-1: Types of Medication Errors

\begin{tabular}{|l|l|l|}
\hline Types of Errors & Number $(\mathbf{N}=\mathbf{5 3})$ & Percentage \\
\hline Prescription error & 16 & $30.18 \%$ \\
\hline Dispensing error & 12 & $22.64 \%$ \\
\hline Documentation error & 9 & $16.98 \%$ \\
\hline Transcription and administration error & 5 & $9.43 \%$ \\
\hline Transcription error & 4 & $7.54 \%$ \\
\hline Billing and dispensing error & 2 & $3.77 \%$ \\
\hline Billing error & 2 & $3.77 \%$ \\
\hline Patient identification error & 2 & $3.77 \%$ \\
\hline Transcription and documentation error & 1 & $1.88 \%$ \\
\hline
\end{tabular}

Table-2: Causes of Prescription errors

\begin{tabular}{|l|l|l|l|}
\hline SL. No & Parameters & Number $(\mathbf{N}=16)$ & Percentage \\
\hline 1 & Therapeutic duplication & 6 & $37.5 \%$ \\
\hline 2 & Wrong dose & 5 & $31.25 \%$ \\
\hline 3 & Illegible & 2 & $12.5 \%$ \\
\hline 4 & Patient details not identifiable & 1 & $6.25 \%$ \\
\hline 5 & Wrong frequency & 1 & $6.25 \%$ \\
\hline
\end{tabular}

Table-3: Causes of Dispensing errors

\begin{tabular}{|l|l|l|l|}
\hline SL No & Parameters & Number $(\mathbf{N}=12)$ & Percentage \\
\hline 1 & Wrong drug & 9 & $75 \%$ \\
\hline 2 & Wrong dose & 3 & $25 \%$ \\
\hline 3 & No label & 1 & $8.33 \%$ \\
\hline 4 & Expired drug/not good condition drug & 1 & $8.33 \%$ \\
\hline 5 & Wrong route & 1 & $8.33 \%$ \\
\hline
\end{tabular}




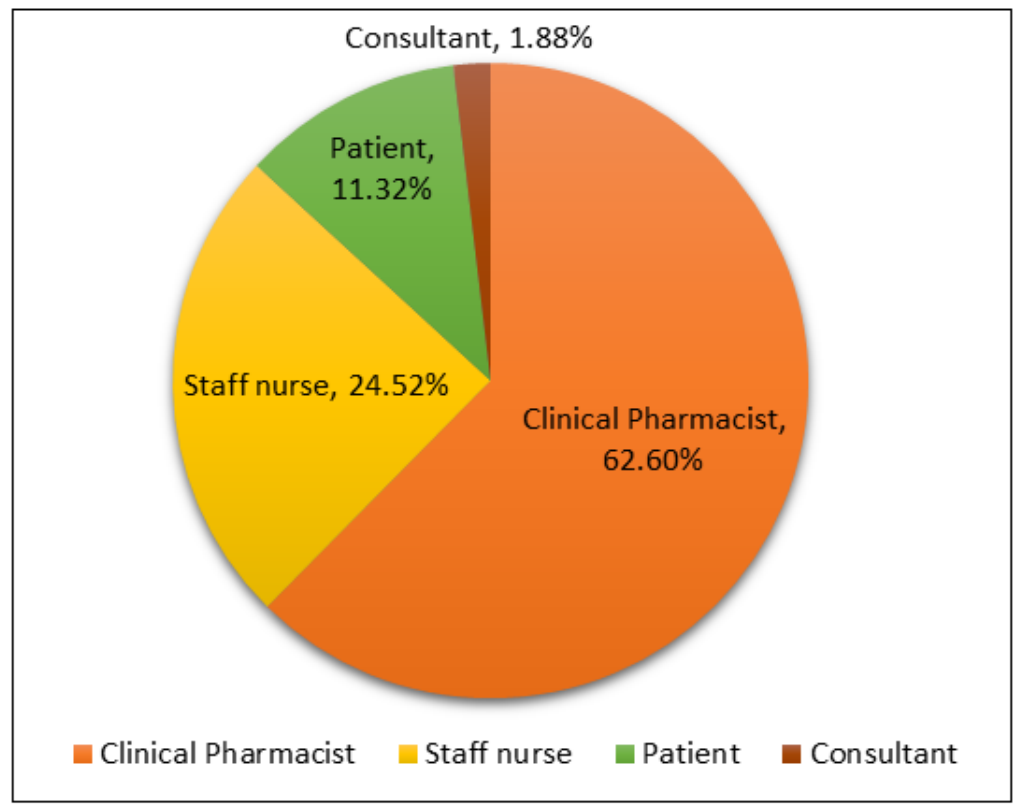

Fig-1: Medication errors reported by specific persons

Table-4: Classification of medication errors

\begin{tabular}{|l|c|r|}
\hline \multicolumn{1}{|c|}{ Class of drugs } & Number of drugs $(\mathrm{n}=53)$ & Percentage \\
\hline CVS drugs & 11 & $20.7 \%$ \\
\hline Antibiotics & 7 & $13.2 \%$ \\
\hline Anti thrombolytic & 6 & $11.3 \%$ \\
\hline CNS drugs & 5 & $9.43 \%$ \\
\hline Vitamin supplements & 5 & $9.43 \%$ \\
\hline Respiratory drugs & 4 & $7.54 \%$ \\
\hline Anti histamines & 4 & $7.54 \%$ \\
\hline Sedative and hypnotics & 4 & $7.54 \%$ \\
\hline Analgesic / NSAID & 3 & $5.6 \%$ \\
\hline Steroids & 2 & $3.77 \%$ \\
\hline Diuretics & 1 & $1.88 \%$ \\
\hline Anti malarial & 1 & $1.88 \%$ \\
\hline
\end{tabular}

Table-5: Severity classification of medication error

\begin{tabular}{|l|l|c|c|}
\hline Level of severity & Category type & No of medication errors & Percentage of medication errors \\
\hline No error & Category A & 11 & $13.5 \%$ \\
\hline Error no harm & Category B & 61 & $75.3 \%$ \\
& Category C & 9 & $11 \%$ \\
& Category D & 00 & $00 \%$ \\
\hline Error harm & Category E & 1 & $1.2 \%$ \\
& Category F & 00 & $00 \%$ \\
& Category G & 00 & $00 \%$ \\
& Category H & 00 & $00 \%$ \\
\hline Error death & Category I & 00 & $00 \%$ \\
\hline
\end{tabular}

\section{CONCLUSION}

Pharmacists have an indispensable role in ensuring medication safety across the continuum of care. These medication errors could directly inflict damage upon the patient and increase health care costs and could indirectly harm the healthcare personnel on professional and personal levels and reduce their self-esteem and performance.

The complexity of the medication prescribing and delivery processes can make it difficult to prove the beneficial effect of pharmacists on adverse outcomes directly, but pharmacist involvement has been shown to reduce errors, improve prescribing practices, and enhance patient monitoring across settings. 
Educational programmes for drug prescribers and nurses concerning drug therapy are urgently needed to avoid drug errors and to improve patient safety by clinical pharmacists and clinical pharmacologists. The following recommendations are suggested to allow decision-makers to improve medication safety and reduce MEs:

- Increase the awareness of MEs of health care professionals.

- $\quad$ Prescribers need to pay more attention to drug dosing.

- Improve medication error reporting systems and policy among Organization by removing barriers, clarifying the importance of reporting and encouraging health care professionals to report medication errors.

- Clinical consequences of MEs should be assessed and evaluated in future studies.

- Carry out regular intensive educational and training programmes in pharmacotherapy for undergraduate medical and paramedical students.

- Educational programmes by clinical pharmacists and clinical pharmacologists on drug therapy are urgently needed for doctors and nurses.

\section{REFERENCE}

1. Ogunleye, O. O., Oreagba, I. A., Falade, C., Isah, A., Enwere, O., Olayemi, S., ... \& Obodo, J. (2016). Medication errors among health professionals in Nigeria: a national survey. International Journal of Risk \& Safety in Medicine, 28(2), 77-91.

2. Van Harten, W. H., \& Manen, J. V. (2009). The Occurrence of Medication Errors and the Occurrence of Risk Factors for Medication Errors in State Hospitals in Ghana: Patient's Safety Improvement in Focus. Healthcare Management, 1-74.

3. Lustig, A. (2000). Medication error prevention by pharmacists- An Israeli solution. Pharmacy World and Science, 22(1), 21-25.

4. Karthikeyan, M., Balasubramanian, T., Khaleel, M. I., Sahl, M., \& Rashifa, P. (2015). A systematic review on medication errors. International Journal of Drug Development and Research, 7(4), 9-11.

5. Barker, K. N., Flynn, E. A., Pepper, G. A., Bates, D. W., \& Mikeal, R. L. (2002). Medication errors observed in 36 health care facilities. Archives of internal medicine, 162(16), 1897-1903.

6. Chalasani, S. H., Ramesh, M., \& Gurumurthy, P. (2018). Pharmacist-Initiated Medication Error-Reporting and Monitoring Programme in a Developing Country Scenario. Pharmacy, 6(4), 133.

7. Reddy, K. S. (2018). A Study on Role of Clinical Pharmacist in Identification and Prevention of Medication Errors at a Teritiary Care Hospital. Indian Journal of Pharmacy Practice, 11(4), 199. 